\title{
Teor e rendimento de flavonóides em calêndula (Calendula officinalis L.) cultivada com diferentes lâminas de irrigação
}

\author{
BORTOLO, D.P.G; MARQUES, P.A.A.; PACHECO, A.C.* \\ UNOESTE - Rodovia Raposo Tavares, km 572, CEP: 19067-175, Presidente Prudente-Brasil. danipgbortolo@ \\ hotmail.com pmarques@unoeste.br *anaclau@unoeste.br
}

\begin{abstract}
RESUMO: A Calendula officinalis L. apresenta uso ornamental, culinário e terapêutico. A inflorescência é usada com ação cicatrizante e antiinflamatória. O experimento analisou o efeito de quatro lâminas de irrigação em condições de campo, na produção de flavonóides em calêndula. As lâminas baseadas na evaporação do Tanque Classe A (ECA) foram: 0, 50, 100 e 150\% ECA; sendo aplicadas desde o início do florescimento até o final do ciclo da cultura. O teor de flavonóides não apresentou diferenças estatísticas. Os maiores valores de matéria seca de flores e rendimento de flavonóides foram obtidos no tratamento sem irrigação. O teor de prolina foi maior para o tratamento com estresse por excesso hídrico. A deficiência hídrica acumulada para o tratamento sem irrigação sinalizou uma possível morte por deficiência hídrica. Com a ocorrência da precipitação no período de pré-florescimento, a planta, originária do Mediterrâneo, respondeu com florescimento abundante em massa e em número de flores. Assim, para Presidente Prudente, caso não ocorra a reposição hídrica do solo por precipitação, é necessário o uso de irrigação complementar com $200 \mathrm{~mm}$ apenas no período de pré-florescimento, para induzir ao máximo florescimento e máximo rendimento de flavonóides por hectare.
\end{abstract}

Palavras-chave: Calendula officinalis, manejo da irrigação, tanque classe $\mathrm{A}$

\begin{abstract}
Flavonoid content and yield in marigold plant (Calendula officinalis L.) cultivated under different irrigation depths. Calendula officinalis $L$. presents ornamental, culinary and therapeutic use. Its inflorescence is used to heal and as an anti-inflammatory. This study analyzed the effect of four different irrigation depths under field conditions on flavonoid production in marigold plant (Calendula officinalis $L$.). The water depths were estimated based on the class A pan evaporation (CPE): 0, 50, 100 and 150\% CPE; they were applied from the beginning of flowering to the end of the culture cycle. There were no statistical differences in flavonoid content. The highest values of flower dry weight and flavonoid yield were obtained with the treatment without irrigation. The highest proline content was found in the plants subjected to overwatering stress. The accumulated water deficit for the treatment without irrigation signalized possible death due to water deficit. As precipitation occurred in the pre-flowering, the plant, originated from Mediterranean, responded with an abundant flowering in mass and number of flowers. Thus, for Presidente Prudente (São Paulo State, Brazil), if there is no water replacement through precipitation, supplementary irrigation with $200 \mathrm{~mm}$ will be necessary only in the pre-flowering to induce maximum flowering and maximum flavonoid yield per hectare.
\end{abstract}

Key words: Calendula officinalis, irrigation scheduling, class A pan evaporation

\section{INTRODUÇÃO}

A planta Calendula officinalis L. pertence à família Asteraceae e é conhecida como mal-me-quer ou maravilha dos jardins. É uma espécie originária do Mediterrâneo, caracterizado por verões quentes e secos e invernos frios e pouco chuvosos (Martins et al., 2000). Além da utilização ornamental, tem uso culinário e terapêutico. Sua inflorescência é a parte da planta mais usada com fins terapêuticos, com ação cicatrizante, antiinflamatória e antisséptica (Martins et al., 2000; Hamburguer et al., 2003). Entre

Recebido para publicação em 29/08/2008

Aceito para publicação em 03/06/2009

Rev. Bras. PI. Med., Botucatu, v.11, n.4, p.435-441, 2009. 
os constituintes químicos potencialmente ativos da calêndula, são citados óleo essencial, saponinas, flavonóides, carotenóides, mucilagens, resinas e princípio amargo. Contudo, os flavonóides têm papel mais importante na atividade farmacológica das flores de calêndula, representados na grande maioria pelos compostos quercetina e rutina, também usados como marcadores para aferir a qualidade da matéria prima (Bilia et al., 2002; Rodrigues et al., 2004).

Dentre as funções fisiológicas dos princípios ativos nas plantas é citada a ação protetora em relação a estresses ambientais, como aqueles associados com mudanças de temperatura, conteúdo de água, intensidade de luz, exposição à radiação UV e deficiência nutricional (Castro et al., 2005).

Uma planta medicinal, se cultivada sob diferentes condições hídricas, pode apresentar alterações qualitativas e quantitativas no metabolismo secundário. Para determinar se a alteração foi benéfica ou prejudicial, deve ser feita uma análise química baseada na relação massa seca/ teor de princípios ativos, o que estabelecerá se a alteração no manejo de cultivo foi adequada ou não (Montanari Junior, 2000; Santos et al., 2004).

Em práticas agrícolas, a deficiência hídrica pode ser compensada com a irrigação. Porém, por ser um método caro, a irrigação deve ser feita de maneira correta para evitar o desperdício e não prejudicar o desenvolvimento da planta, já que o excesso de água no solo causa redução imediata na troca de gases entre a planta e o ambiente (Armstrong et al., 1994). Este processo, conhecido como anoxia ou hipoxia, sofrido pelo sistema radicular, altera o metabolismo celular, provocando queda imediata na respiração das raízes, tanto em plantas tolerantes como nas susceptíveis (Liao \& Lin, 2001). De acordo com Gutiérrez (2006), este estresse ambiental promove a formação de etileno devido à privação de $\mathrm{O}_{2}$, acarretando sintomas morfológicos e fisiológicos de situação de estresse. Pardos (2004) completa que os danos nos tecidos submetidos temporariamente ao encharcamento levam a disfunções enzimáticas e fechamento estomático.

A resposta das plantas à tensão de água no solo tem sido estudada como forma de controle da irrigação, já que irrigações deficitárias causam redução da produtividade, enquanto irrigações excessivas prejudicam a qualidade das flores (Farias, 2006). Silva et al. (2002) observaram que em Melaleuca altermifolia Cheel a deficiência hídrica diminuiu o crescimento, a produção de biomassa seca das plantas e o teor de óleo essencial. Ahmed \& El-Hassen (2001) relataram para dois cultivares de vinca (Catharanthus roseus) que com o aumento do intervalo de irrigação a altura da planta foi significativamente reduzida, já o número de ramos, o peso seco de raízes, a produção de folhas e o conteúdo de alcalóides foi maior. El-Din (2003), avaliando o anis (Pimpinella anisum), observou que o déficit hídrico proporcionou a maior produção de frutos e conteúdo de óleo essencial. Singh (2004), estudando alecrim (Rosmarinus officinalis), obteve com $50 \%$ de evaporação do tanque classe A o maior crescimento e produção de óleo, porém não houve diferenças no teor nem na qualidade do óleo. Segundo Carvalho et al. (2005), a diminuição na disponibilidade hídrica do substrato reduziu o teor de partenolídeo em plantas de artemísia ( Tanacetum parthenium).

Em condições de estresse hídrico, vários processos fisiológicos são alterados, tais como: fotossíntese, abertura estomática, produção de ácido abscísico, abscisão foliar e ajuste osmótico (Taiz \& Zeiger, 2004). As plantas cultivadas sob níveis reduzidos de água no solo diminuem o crescimento e investem no ajuste osmótico. Dentre os solutos envolvidos no processo de ajustamento osmótico, a prolina tem aparecido na literatura como sendo um aminoácido particularmente sensível ao estresse (Hopkins, 1995; Larcher, 2004), usado como estratégia para se adaptar à condição de estresse hídrico (Singh-Sangwan et al., 1994). De acordo com Machado Neto et al. (2004), o acúmulo de aminoácidos, como a prolina, pode ser utilizado para avaliar as alterações enzimáticas ocorridas como respostas bioquímicas para mudanças no ambiente tais como temperatura, déficit hídrico, encharcamento e salinidade.

A pesquisa proposta teve por objetivo estudar os efeitos de diferentes lâminas de irrigação sobre a produção de inflorescências, o teor de prolina e o teor e rendimento de flavonóides em plantas de calêndula (Calendula officinalis L.) cultivadas a campo na região de Presidente Prudente.

\section{MATERIAL E MÉTODO}

A pesquisa foi conduzida na área experimental de Plantas Medicinais da UNOESTE em Presidente Prudente-SP, latitude 2207'04"S; longitude 5122' 05 "W e altitude de 435,5 m; no período de abril a setembro de 2007. O clima é, pela classificação de Köppen, Aw mesotérmico, com verões quentes e invernos secos. O solo é classificado como Argissolo Vermelho-Amarelo, Eutrófico, de textura arenosa/média (Embrapa, 1999). Apresentase na Tabela 1 a análise físico-química do solo realizada conforme Raij et al. (2001). O solo do experimento não recebeu adubação nem calagem por tratar-se de área comumente utilizada para plantio de espécies olerícolas, com soma de bases próxima a $70 \%$ e teores de nutrientes adequados (Raij et al., 1996).

As mudas de calêndula (Calendula officinalis L.), cv. Dobrada Sortida, foram obtidas por semeadura em bandejas de polipropileno de 200 células (12,39 
TABELA 1. Análise físico-química do solo.

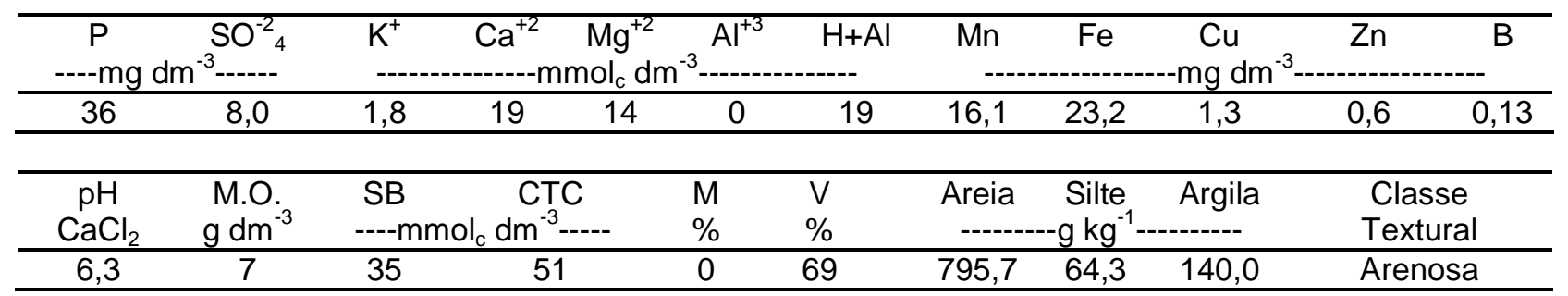

M.O. - matéria orgânica; S.B. - soma de bases; CTC - capacidade de troca de cátions; M\% - saturação por alumínio; VB\% - saturação por bases.

$\mathrm{cm}^{3}$ ), com 2 sementes por célula. Aos 20 dias após semeadura (DAS) as mudas atingiram altura de 8 $\mathrm{cm}$, passando pelo processo de desbaste deixandose uma planta por célula. As plantas permaneceram nas bandejas por mais 5 dias e depois foram transplantadas para copos de $300 \mathrm{~mL}$ contendo substrato comercial, permanecendo mais 15 dias em viveiro e recebendo irrigação manual três vezes ao dia. O solo da área foi preparado por gradagem e em seguida, os canteiros foram erguidos manualmente, resultando em 20 parcelas de $2,25 \mathrm{~m}^{2}$, que foram separadas por barreira física de placas de eucatex, com $0,5 \times 1,0 \mathrm{~m}$, a fim de impedir a transferência de umidade entre as mesmas. $\mathrm{Na}$ preparação dos canteiros foram aplicados $150 \mathrm{~kg}$ de húmus de minhoca distribuindo-se $3 \mathrm{~kg} \mathrm{~m}^{-2}$. $\mathrm{O}$ transplantio foi realizado em covas de $20 \mathrm{~cm}$ de profundidade com espaçamento de 0,30 x 0,50 m aos 40 DAS. As parcelas constaram de 15 plantas. Após o plantio, colocaram-se restos de silagem de capim napier, como cobertura orgânica. Durante o ciclo, os tratos culturais realizados constaram de capina manual e controle de infestação de formigas, utilizando-se iscas.

O experimento foi instalado em delineamento inteiramente casualizado, com quatro tratamentos de lâminas de irrigação baseadas na evaporação do tanque classe $A$ (ECA), o qual é um dos métodos mais utilizados para estimativa da evapotranspiração (ETo), desenvolvido pelo Serviço Meteorológico NorteAmericano, onde se mede o efeito integrado da radiação solar, vento, temperatura e umidade relativa sobre a evaporação de superfície livre de água, no qual a planta responde as mesmas variáveis climáticas (Doorenbos \& Pruitt, 1984). Os tratamentos foram: T1 - 0\% (sem irrigação); T2 - 50\%; T3 - 100\% e T4 - 150\% ECA, com cinco repetições. Utilizou-se irrigador manual com calibrações a cada $500 \mathrm{~mL}$ por meio do qual a água foi distribuída diariamente no período da manhã e de maneira uniforme. As lâminas de irrigação (Equação 01) foram estimadas com base nas leituras realizadas diariamente, sendo: hi a lâmina de irrigação (L); ECA a evaporação do tanque classe $A(\mathrm{~mm}) ; \mathrm{Kp}$ o coeficiente do tanque classe $A ; \mathrm{kc} o$ coeficiente da cultura (Allen et al., 1998) e S a área do canteiro $\left(2,25 \mathrm{~m}^{2}\right)$.

$$
\mathrm{hi}=\mathrm{ECA} \cdot \mathrm{kp} \cdot \mathrm{kc} \cdot \mathrm{S}
$$

A colheita da linha central foi iniciada após 60 dias do transplantio (DAT), com o surgimento das primeiras flores, sendo realizadas duas vezes por semana até a senescência das plantas. Em cada colheita, as flores foram secas em estufa com circulação de ar à temperatura de 40 graus até a obtenção de peso constante, para a determinação da massa de matéria seca de flores (MSF). As flores secas permaneceram armazenadas em papel "Kraft" até o momento da análise fitoquímica (evitando a interferência de luz e umidade). Ao final do período de colheita (120 DAT), os valores de todas as colheitas foram somados, obtendo-se a massa de matéria seca total de flores (MSTF).

A dosagem de flavonóides foi realizada de acordo com Verlag (1978) modificado, em dois gramas de material seco e pulverizado (capítulos florais), utilizando-se quercetina como padrão, em solução de metanol e cloreto de alumínio. Realizou-se a leitura a $420 \mathrm{~nm}$, em espectrofotômetro UV/visível Beckman DU 70. A obtenção do teor de prolina nas folhas foi realizada de acordo com Bates et al. (1973), a partir de amostras de $500 \mathrm{mg}$ de massa de matéria fresca de folhas (MMF).

Para as variáveis analisadas, onde houve diferenças estatísticas pelo teste de Scott-Knott com $5 \%$ de probabilidade, as regressões para as lâminas de água foram calculadas pelo software Sisvar utilizando todas as repetições.

\section{RESULTADO E DISCUSSÃO}

No período estudado, no qual a planta permaneceu no campo, ocorreu uma precipitação efetiva de $200 \mathrm{~mm}$, distribuídos no período de 16 a 22 de julho de 2008. No restante do período não se observou precipitação efetiva. Na Figura 1 é apresentado o balanço hídrico climatológico mensal, de acordo com Pereira et al. (2002), iniciado com o solo em capacidade de campo após irrigação das parcelas aos sete dias após o transplantio, para o período de abril a setembro de 2007, considerando a capacidade de retenção de água do solo (CAD) da região de Presidente Prudente de $100 \mathrm{~mm}$. Neste 
balanço hídrico consta a indicação do período do florescimento no qual ocorreram as colheitas. A lâmina total de irrigação aplicada para cada tratamento foi de $0 \mathrm{~mm} ; 59,5 \mathrm{~mm} ; 119,00 \mathrm{~mm}$ e $178,5 \mathrm{~mm}$ para $0 \% \mathrm{ECA}$; $50 \%$ ECA; $100 \%$ ECA e 150\% ECA respectivamente.

As respostas da planta à escassez de água são complexas. Sob condições de campo, estas respostas podem ser sinérgica ou antagonicamente modificadas pela imposição de outros estresses. As estratégias da planta para lidar com a seca normalmente envolvem uma mistura de mecanismos de tolerância e evitância, os quais variam com o genótipo. Entretanto, é a resposta integrada, isto é, ao nível da planta como um todo, a qual irá ditar a sobrevivência em ambiente estressante. Essa resposta integrada inclui a assimilação de carbono e alocação de fotoassimilados para as diferentes partes da planta e também a habilidade reprodutiva da planta (Chaves et al., 2002; Larcher, 2004).

Uma das manifestações não específicas do estado de estresse, ou seja, independente da natureza do agente estressor, é o aparecimento de substâncias osmoticamente ativas, como a prolina. De acordo com Larcher (2004), sob a influência do estresse, a síntese de proteínas é inibida e a degradação de proteínas é acelerada, o que leva a um acúmulo de aminoácidos e aminas livres. Característica marcante de um distúrbio no metabolismo das proteínas é a mudança nas proporções dos aminoácidos e, freqüentemente, um aumento elevado na concentração de prolina. Na Figura 2 é apresentado o teor de prolina nas folhas da calêndula em função das diferentes lâminas de irrigação, determinado ao final do ciclo da cultura.

O maior teor de prolina (Figura 2) foi encontrado com o estresse ambiental de excesso hídrico (150\% ECA, equivalente a 178,5 mm). Observase que o excesso de água aplicado diariamente prejudicou o desenvolvimento da cultura, semelhante aos resultados obtidos por Pizard et al. (2006) para camomila, e Silva et al. (2002) para Melaleuca alternifolia. Isto provavelmente ocorreu devido ao excesso diário de água no solo, o qual pode ter causado redução imediata na troca de gases entre a
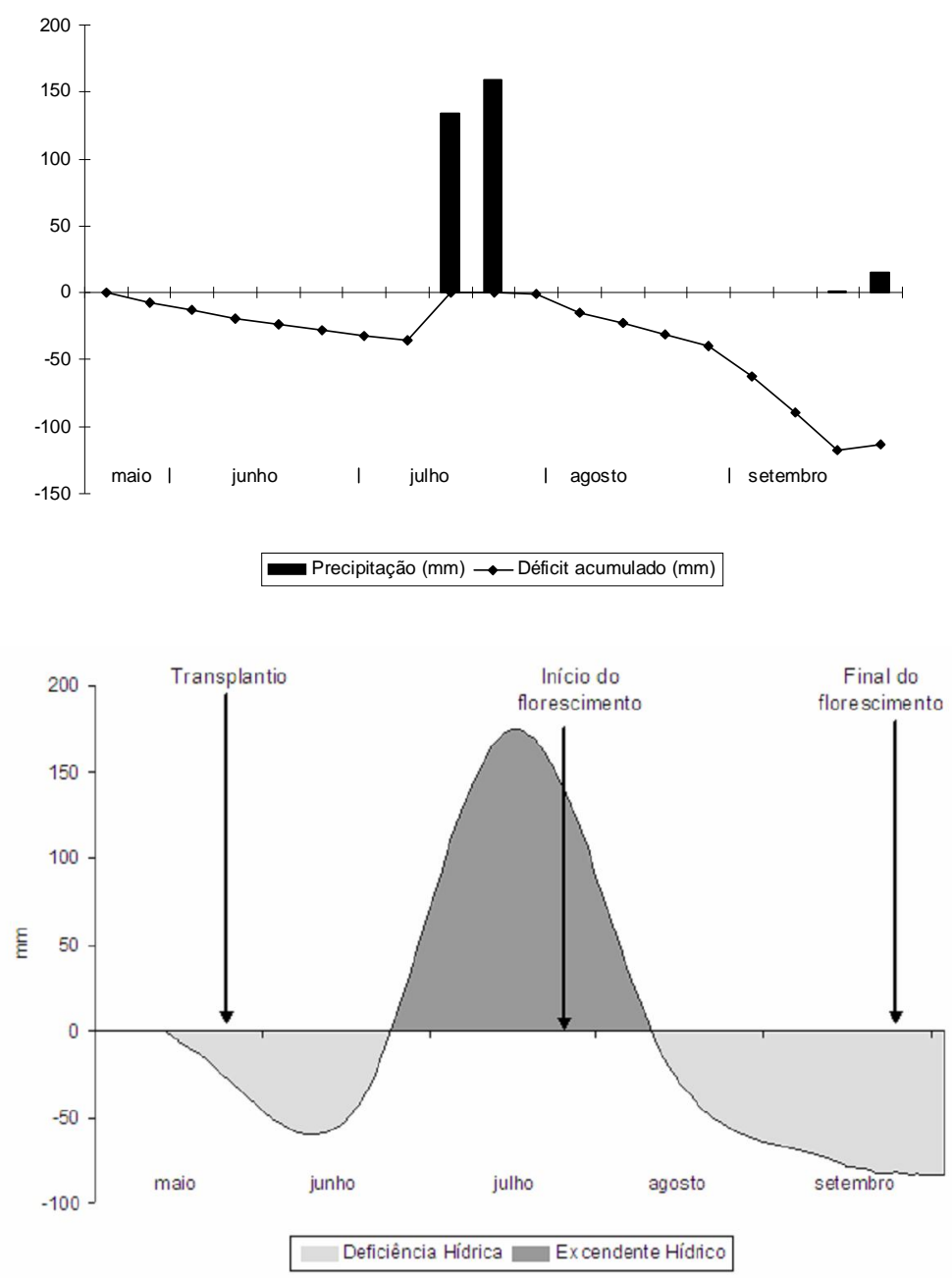

B

FIGURA 1. (A) Precipitação ocorrida e evapotranspiração acumulada para o tratamento sem irrigação e (B) Balanço hídrico para Presidente Prudente para o período no qual a planta permaneceu a campo (maio a setembro de 2007). 
planta e o ambiente, reduzindo o suprimento de oxigênio às raízes e desta forma limitando a respiração, a absorção de nutrientes e outras funções das mesmas (Armstrong et al., 1994; Hopkins, 1995; Pardos, 2004). Kumar \& Singh (1998) explicam que o ajustamento osmótico é um importante mecanismo de tolerância à seca, porque capacita a planta a continuar com o seu crescimento normal e produção rentável, por meio da realização de ajustes estomáticos e fotossintéticos.

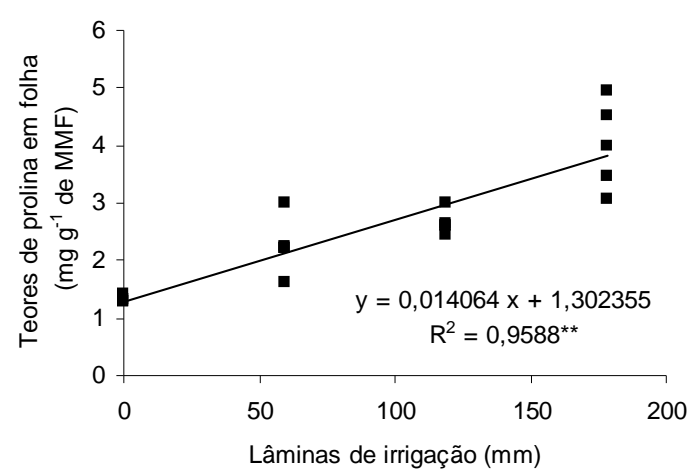

FIGURA 2. Efeito das lâminas de irrigação sobre o teor de prolina na massa de matéria fresca de folhas (MMF) de calêndula (Calêndula officinalis L.) ao final do ciclo.

Esperava-se que o tratamento sem irrigação (T1) também apresentasse alto teor de prolina como resposta ao lento desenvolvimento de deficiência hídrica que pode induzir ao ajustamento osmótico. Porém observou-se o menor teor de prolina neste tratamento, o que pode ser explicado por um provável desvio da rota metabólica ocorrido no período do préflorescimento, devido a origem da planta. Isto foi desencadeado pela ocorrência da precipitação efetiva de $200 \mathrm{~mm}$, a qual promoveu reposição hídrica no solo para todos os tratamentos. Segundo Chaves et al. (2002), plantas herbáceas originárias de clima mediterrâneo, como a calêndula, estão preparadas para responder a mudanças climáticas bem definidas

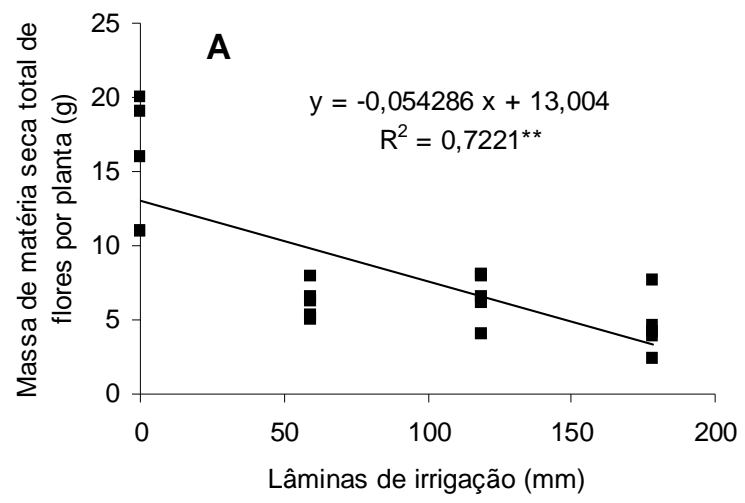

e apresentam relativa tolerância à desidratação de seus tecidos, levando a uma considerável resistência do aparato fotossintético à condição de seca, especialmente nas folhas mais jovens. Ainda, em experimentos a campo, a combinação de fatores de estresse pode reforçar, diminuir, mascarar ou mesmo reverter a resposta da planta a um simples fator de estresse (Larcher, 2004).

No decorrer do ciclo, o Tratamento 1 (sem irrigação - 0\% ECA) esteve sob deficiência hídrica total, o que sinalizou para a planta a possível morte por falta de água. Com a ocorrência da precipitação em julho, no período de pré-florescimento, a planta respondeu imediatamente com um florescimento abundante tanto em massa (Figura 3A) como em número de flores (Figura 3B), buscando a preservação da espécie. Resultados semelhantes foram obtidos por El-Din (2003) em anis (Pimpinella anisum), onde o déficit hídrico proporcionou maior produção de frutos.

Distúrbios na região da raiz, como a deficiência hídrica, acarretam ajustes na distribuição de assimilados e na floração ("floração de emergência"), dentre outros (Andrade \& Casali, 1999; Larcher, 2004). Define-se essa resposta como um dos mecanismos de resistência conhecido como fuga da seca, definida como sendo a habilidade de uma planta de terminar o ciclo de vida antes que o solo atinja déficit hídrico crítico. Este mecanismo envolve o desenvolvimento fenológico rápido (como florescimento e maturação precoce) e a plasticidade no desenvolvimento (variação na duração do período do crescimento, dependendo da extensão do déficit hídrico) (Meneses et al., 2006). Dessa maneira, para o tratamento sem irrigação, a prolina que estava estocada nas plantas pode ter sido utilizada como fonte de $\mathrm{Ne} \mathrm{C}$ para o florescimento, como explicado em Machado Neto et al. (2004).

Os maiores valores de florescimento (Figuras $3 \mathrm{~A}$ e $3 \mathrm{~B}$ ) foram encontrados no tratamento sem irrigação (15,4 g por planta, equivalente a $1026,68 \mathrm{~kg}$ ha $^{-1}$ de inflorescências secas). Esta produtividade

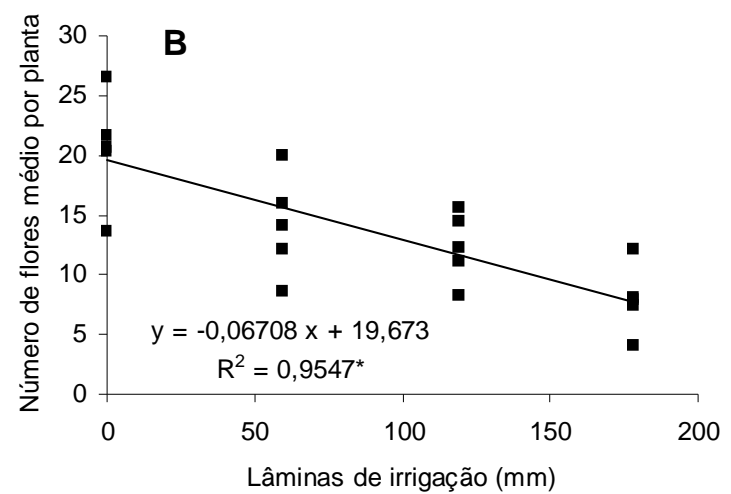

FIGURA 3. Efeito das lâminas de irrigação no florescimento da calêndula (Calêndula officinalis L.) na $(A)$ massa de matéria seca total de flores e (B) no número de flores. 
está de acordo com os valores esperados de $720 \mathrm{~kg}$ ha $^{-1}$ de inflorescências secas, podendo chegar a 2000 $\mathrm{kg} \mathrm{ha}^{-1}$, citados por Montanari Júnior (2000). Os demais tratamentos apresentaram umidades crescentes no solo; assim a planta respondeu com florescimento no período esperado, porém sem a necessidade de rápida e abundante produção de flores para garantir a reprodução da espécie. Os menores valores foram encontrados para o tratamento com $150 \%$ ECA $(178,5 \mathrm{~mm})$, observando-se produtividade com valor inferior ao esperado, de $4,51 \mathrm{~g}$ de inflorescências secas por planta, equivalente a 301,16 $\mathrm{kg} \mathrm{ha}^{-1}$.

No que diz respeito ao efeito da água sobre a formação de compostos fenólicos na planta (entre eles, os flavonóides), pouco é sabido. Em geral, o estresse hídrico pode promover aumento na biossíntese de compostos fenólicos (Matern \& Grimmig, 1994).

Para o teor de flavonóides (Figura 4A), as lâminas de irrigação não interferiram nos valores obtidos, ou seja, a variação da disponibilidade hídrica causada pelos tratamentos não interferiu no metabolismo secundário da planta. Esses resultados são semelhantes aos obtidos por Pacheco (2007), nos quais não houve diferença significativa entre diferentes intensidades de deficiência hídricas testadas (representadas por intervalos de interrupção da irrigação) e o tratamento controle (plantas irrigadas) com relação ao teor de flavonóides totais em inflorescências de calêndula. Também Singh (2004), estudando alecrim (Rosmarinus officinalis L.) sob diferentes regimes de irrigação, observou que a fração de reposição de água não interferiu no teor de óleo essencial.

Em termos fisiológicos, sugere-se que o estresse pode atuar redirecionando o carbono fixado fotossintéticamente da síntese de metabólitos primários, tais como celulose, lipídeos e proteínas (os quais estão associados ao metabolismo de crescimento) para a síntese de metabólitos secundários como flavonóides e outros compostos

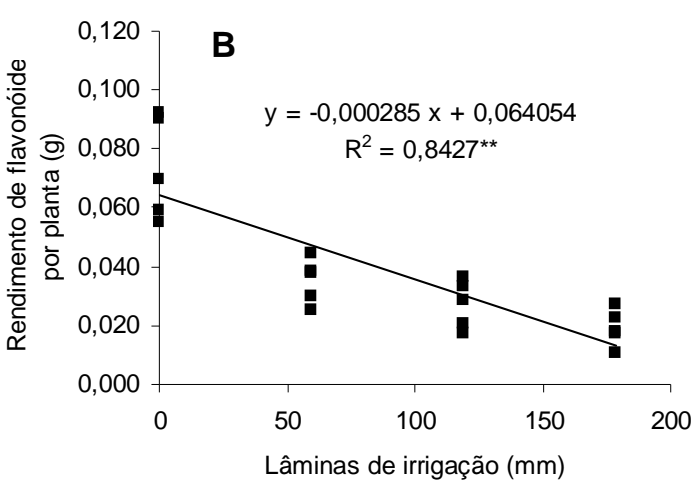

FIGURA 4. Teor (A) e rendimento (B) de flavonóides para a calêndula (Calêndula officinalis L.) sob diferentes lâminas de irrigação.

fenólicos (com pouca ou nenhuma influência sobre o crescimento da planta), sob condições de estresses ambientais (Kirakosyan et al., 2004; Abreu \& Mazzafera, 2005). Assim, para a planta de calêndula, sugere-se que a variação na disponibilidade hídrica testada neste experimento não foi suficiente para promover esse redirecionamento do carbono fixado.

Como os tratamentos influenciaram significativamente a MSF, o rendimento de flavonóides (Figura 4B) também apresentou resposta linear negativa, sendo o maior valor $\left(0,072 \mathrm{~g}\right.$ planta $\left.^{-1}\right)$ obtido para o tratamento sem irrigação e o menor $(0,0019 \mathrm{~g}$ planta $^{-1}$ ) para o tratamento com excesso hídrico (150\%ECA equivalente a $178,5 \mathrm{~mm}$ ).

Concluiu-se que o teor de flavonóides não foi alterado em função das lâminas de irrigação. O maior teor de prolina foi observado com o estresse por excesso hídrico. A produção de flores respondeu linearmente às laminas de irrigação. Dessa maneira, para as condições climáticas da região de Presidente Prudente, o uso da irrigação para o plantio em maio não é necessário. Caso não ocorra precipitação, a irrigação deve ser realizada apenas no período de préflorescimento, com lâmina de aproximadamente $200 \mathrm{~mm}$.

\section{REFERÊNCIA}

ABREU, I.N.; MAZZAFERA, P. Effect of water and temperature stress on the content of active constituents of Hypericum brasiliense Choisy. Plant Physiology and Biochemistry, v.43, n.3, p.241-8, 2005.

AHMED, A.A.M.; EL-HASSEN, G.M. Effect of water regime and cultivar on herbage yield and alkaloid content of Catharanthus roseus. Journal of Medicinal and Aromatic Plant Sciences, v.23, n.3, p.350-6, 2001. 
ALLEN, R.G. et al. Crop evapotranspiration:guidelines for computing crop water requirements. Roma: FAO, 1998. 301p. (FAO Irrigation and Drainage Paper, 56). ANDRADE, F.M.C.; CASALI, V.W.D. Plantas medicinais e aromáticas: relação com o ambiente, colheita e metabolismo secundário. Viçosa: UFV, 1999. 139p. ARMSTRONG, W. et al. Mechanisms of flood tolerance in plants. Acta Botanica Neerlandica, v.43, p.307-58, 1994. BATES, L.E. et al. Rapid determination of free proline for water-stress studies. Plant and Soil, v.39, p.205-7, 1973. BILIA, A.R. et al. Stability of the constituents of calendula, milk-thistle and passionflower tinctures by LC-DAD and LC-MS. Journal of Pharmaceutical and Biomedical Analysis, v.30, n.3, p.613-24, 2002.

CARVALHO, L.M. et al. Crescimento, teor de partenolídeo e de prolina em plantas. Acta Scientiarum - Agronomy, v.27, n.1, p.151-7, 2005.

CASTRO, P.R.C. et al. Manual de fisiologia vegetal. São Paulo: Editora Agronômica Ceres, 2005. 651p.

CHAVES, M.M. et al. How plants cope with water stress in the field? Photosynthesis and growth. Annals of Botany, v.89, n.7, p.907-16, 2002.

DOORENBOS, J.;PRUITT, W.O. Guidelines for predicting crop water requirements. Rome: FAO. Irrigation and Drainage, 1984. 144p. (Paper, 24).

EL-DIN, A.A.E. Growth, yield and essential oil of anise in relation to water supply. Annals of Agricultural Science, v.48, n.2, p.777-85, 2003.

EMBRAPA, Sistema brasileiro de classificação de solos. Brasília: Embrapa Produção de Informações (SPI), 1999. 412p.

FARIAS, M.F. Manejo da irrigação na cultura do crisântemo (Dendranthema grandiflorum ramat kitamura) de corte cultivado em ambiente protegido. 2006. 93p. Tese (Doutorado em Agronomia) - Universidade Estadual Paulista, Faculdade de Ciências Agrárias e Veterinárias, Botucatu.

GUTIÉRREZ, G.C. Muerta celular programada como respuesta al estrés ambiental. Revista Chapingó, v.12, n.2, p.93-9, 2006.

HAMBURGUER, M. et al. Preparative purification of the major anti-inflamatory triterpenoid ester from Marigold (Calendula officinalis). Fitoterapia, v.74, p.328-38, 2003. HOPKINS, W.G. Introduction to Plant Physiology. New York: John Wiley \& Sons, 1995. 464p.

KIRAKOSYAN, A. et al. Applied environmental stresses to enhance the levels of polyphenolics in leaves of hawthorn plants. Physiologia Plantarum, v.121, p.182-6, 2004.

KUMAR, A.; SINGH, D.P. Use of physiological indices as a screening technique for drought to tolerance in oilseed Brassica species. Annals of Botany, v.81, s.n., p.413-20, 1998.

LARCHER, W. Ecofisiologia vegetal. São Carlos: RiMa, 2004. 531p.

LIAO, C.T.; LIN, C.H. Physiological adaptation of crop plants to flooding stress. Proceedings of the National Science Council, v.25, p.148-57, 2001.

MACHADO NETO, N.B. et al. Proline: use as indicator of temperature stress in bean seeds. Crop Breeding and Applied Biotechnology, v.4, p.127-34, 2004.

MARTINS, E.R. et al. Plantas medicinais. Viçosa: UFV, 2000. 219p.

MATERN, V.; GRIMMIG, B. Natural phenols as stress metabolites. Acta Horticulturae, n.381, p.448-62, 1994. MENESES, C.H.S.G. et al. Aspectos genéticos e moleculares de plantas submetidas ao déficit hídrico. Revista de Oleaginosas e Fibrosas, v.10, n.1/2, p.103972, 2006.

MONTANARI JUNIOR, I. Aspectos do cultivo comercial de calêndula. Revista Agroecológica, v.1, n.2, p.24-5, 2000. PACHECO, A.C. Deficiência hídrica e aplicação de ABA sobre as trocas gasosas e o acúmulo de flavonóides em calêndula (Calendula officinalis L.). 2007.61p. Tese (Doutorado em Fisiologia e Bioquímica de Plantas) Universidade de São Paulo, Piracicaba.

PARDOS, J.A. Respuestas de las plantas al anegamiento del suelo. Sistemas y Recursos Forestales, s.n., p.1017, 2004.

PEREIRA, A.R. et al. Agrometeorologia: fundamentos e aplicações práticas. Guaíba: Agropecuária, 2002. 478p. PIZARD, A. et al. Essential oil content and composition of german chamomile (Matricaria chamomilla L.) at different irrigation regimes. Journal of Agronomy, v.5, n.3, p.451-5, 2006.

RAIJ, B.V. et al. Recomendações de adubação e calagem para o Estado de São Paulo. 2.ed. Campinas: Instituto Agronômico \& Fundação IAC, 1996. 285p. (Boletim técnico, 100)

RAIJ, B.V. et al. Análise química para avaliação de fertilidade de solos tropicais. Campinas: Instituto agronômico, 2001. 285p.

RODRIGUES, P.O. et al. Influência de diferentes sistemas de solventes no processo de extração de Calendula officinalis L. (Asteraceae). Acta Farmaceutica Bonaerense, v.23, n.1, p.27-31, 2004.

SANTOS, T.T. et al. Efeito do estresse hídrico na produção de massa foliar e teor de óleo essencial em sambacaitá (Hyptis pectinata L.). In: CONGRESSO BRASILEIRO DE OLERICULTURA, 44., 2004. Campo Grande. Anais... Campo Grande: SOB, 2004. v.22. p.1-4. SILVA, S.R.S. et al. Efeito do estresse hídrico sobre características de crescimento e a produção de óleo essencial de Melaleuca alternifolia Cheel. Acta Scientiarum, v.24, n.5, p.1363-8, 2002.

SINGH, M. Effects of plant spacing, fertilizer, modified urea material and irrigation regime on herbage, oil yield and oil quality of rosemary in semi-arid tropical conditions. The Journal of Horticultural Science and Biotechnology, v.79, n.3, p.411-5, 2004.

SINGH-SANGWAN, N. et al. Effect of drought stress on growth and essential oil metabolism in lemongrasses. New Phytologist, v.128, p.173-9, 1994.

TAIZ, L.;ZEIGER, E. Fisiologia vegetal. 3.ed. Porto Alegre: Art med, 2004. 719p.

VERLAG, D.A. Deustsches Arzeibuch. Stuttgart: GogiVerlag $\mathrm{GmBH}, 1978$. 680p. 